\title{
Analisis Manajemen Bandwidth Hierarchical Token Bucket (HTB) dengan Mikrotik pada Jaringan SMK Negeri 22
}

\author{
Muhammad Iqbal Ichwan ${ }^{1}$, Lipur Sugiyanta ${ }^{2}$, Prasetyo Wibowo Yunanto ${ }^{3}$ \\ 1,2,3 Pendidikan Teknik Informatika dan Komputer Fakultas Teknik \\ Universitas Negeri Jakarta \\ ${ }^{1}$ miqbalichwan@gmail.com, ${ }^{2}$ lipurs@unj.ac.id, ${ }^{3}$ prasetyo.wy@unj.ac.id
}

\begin{abstract}
Abstrak
Penggunaan Bandwidth di sebuah jaringan seringkali kurang dimanfaatkan secara optimal. Salah satu solusi yang efektif untuk mengatasinya adalah dengan mengelola pemakaian bandwidth dengan melakukan manajemen bandwidth. Saat ini SMK Negeri 22 Jakarta menerapkan manajemen bandwidth dengan mikrotik RB 1100AHX2 menggunakan fitur simple queue. Pada penelitian ini dilakukan manajemen bandwidth dengan mikrotik RB 750Gr3 menggunakan fitur queue tree dengan menggunakan metode hierarchical token bucket (HTB). Setelah dilakukan manajemen bandwidth dengan metode HTB, kemudian dilakukan pengukuran Quality of Service (QoS) dengan parameter bandwidth, throughput, delay, dan packet loss. Hasil yang didapat setelah dilakukan manajemen bandwidth dengan metode HTB yaitu pada parameter throughput mengalami kenaikan $2.7746 \%$ pada perangkat pengukuran cnn.com dan $13.3415 \%$ pada facebook.com. Pada parameter packet loss mengalami penurunan $13 \%$ pada cnn.com, $17 \%$ pada facebook.com dan $16 \%$ pada mail.yahoo.com. Pada parameter delay mengalami penurunan dari yang sebelumnya $135 \mathrm{~ms}$ menjadi $41 \mathrm{~ms}$ pada facebook.com dan $108 \mathrm{~ms}$ menjadi $90 \mathrm{~ms}$ pada mail.yahoo.com. Pada indeks nilai akhir mengalami kenaikan dari 2.33 menjadi 2.89 .
\end{abstract}

Kata kunci : Manajemen bandwidth, Hierarchical Token Bucket (HTB)

\section{Pendahuluan}

Dengan semakin banyaknya kebutuhan akan akses dan komunikasi maka kinerja jaringan harus berada pada kondisi yang baik, maka besarnya bandwidth yang dibutuhkan harus dapat memecahkan masalah utama yaitu menyediakan kinerja layanan yang bagus untuk dapat memberikan layanan yang nyaman kepada pengguna. Walaupun bandwidth yang dimiliki sudah cukup besar apabila tidak dilakukan pengaturan maka akan mengakibatkan pemakaian antar user yang tidak seimbang, ada yang cukup cepat dan ada yang lambat bahkan tidak dapat akses sama sekali. Salah satu solusi yang efektif untuk mengatasinya adalah dengan melakukan manajemen bandwidth.

Saat ini smk negeri 22 jakarta menerapkan manajemen bandwidth dengan menggunakan fitur simple queue, dengan membagi bandwidth ke tiaptiap jaringan. Karena bandwidth dibagi ke tiap-tiap jaringan maka setiap klien yang terhubung ke jaringan tersebut akan saling berebut bandwidth.

Tabel 1.1 Hasil Akhir Analisis Dari Ruang Guru

\begin{tabular}{|c|c|c|c|c|}
\hline Web & Average & Persentase & Predikat & Nilai \\
\hline Thn.com & 397516 & 13.2504 & Jelek & 1 \\
\hline facebook.com & 100606 & 3.3535 & Jelek & 1 \\
\hline mail.yahoo.com & 296933 & 9.8976 & Jelek & 1 \\
\hline Web & $\begin{array}{c}\text { Average } \\
\text { Packet loss }\end{array}$ & $\begin{array}{c}\text { Persentase } \\
(\%)\end{array}$ & $\begin{array}{l}\text { Predikat } \\
\text { TIPHON }\end{array}$ & Nilai \\
\hline cnn.com & 58 & 18 & Sedang & 2 \\
\hline facebook.com & 58 & 19 & Sedang & 2 \\
\hline mail.yahoo.com & 58 & 18 & Sedang & 2 \\
\hline Web & Average Delay & $\begin{array}{l}\text { Predikat } \\
\text { TIPHON }\end{array}$ & Nilai \\
\hline cnn.com & \multicolumn{2}{|c|}{71} & $\begin{array}{l}\text { Sangat } \\
\text { Bagus }\end{array}$ & 4 \\
\hline facebook.com & \multicolumn{2}{|c|}{135} & $\begin{array}{l}\text { Sangat } \\
\text { Bagus }\end{array}$ & 4 \\
\hline mail.yahoo.com & \multicolumn{2}{|c|}{108} & $\begin{array}{l}\text { Sangat } \\
\text { Bagus }\end{array}$ & 4 \\
\hline & Hasil penjum lah an & Nilai & 21 \\
\hline & \multicolumn{2}{|c|}{ Dibagi jumlah Parameter yang di } \\
ukur (9) & $21: 9=2.33$ \\
\hline
\end{tabular}

Setelah dilakukan pengukuran Quality of Service (QoS) dengan parameter bandwidth, throughput, 
delay dan packet loss berdasarkan Tabel 1.1 didapatkan indeks hasil akhir sebesar 2.33. Jika dibandingkan dengan standarisasi TIPHON, hasil ini masuk dalam kategori kurang memuaskan. Oleh karena itu penulis membuat manajemen bandwidth dengan metode HTB.

Metode ini dipilih karena metode HTB mempunyai kelebihan dalam pembatasan trafik pada tiap level maupun klasifikasi, sehingga bandwidth yang tidak dipakai oleh level yang tinggi dapat digunakan atau dipinjam oleh level yang lebih rendah (Wijaya, 2013). Jadi apabila ada user yang tidak aktif, bandwidth dapat di pakai atau di pinjam oleh user yang sedang aktif. HTB sangat berguna untuk membatasi rating download dan upload client.

Tujuan dari penelitian adalah untuk menerapkan manajemen bandwidth menggunakan metode HTB pada Routerboard Mikrotik tipe RB750Gr3 agar kualitas layanan QOS di SMK Negeri 22 menjadi lebih baik.

\section{Dasar Teori}

\subsection{Manajemen Bandwidth}

Manajemen berasal dari kata "to manage" yang berarti mengatur, mengurus atau mengelola, sedangkan bandwidth adalah besaran yang menunjukkan seberapa banyak data yang dapat dilewatkan dalam koneksi melalui sebuah network.

Manajemen bandwidth adalah pengalokasian yang tepat dari suatu bandwidth untuk mendukung kebutuhan atau keperluan aplikasi atau suatu layanan jaringan. Pengalokasian bandwidth yang tepat dapat menjadi salah satu metode dalam memberikan jaminan kualitas suatu layanan jaringan QoS = Quality Of Services). (http://overflow.web.id, 2009).

Bandwidth management adalah suatu cara yang dapat digunakan untuk management dan mengoptimalkan berbagai jenis jaringan dengan menerapkan layanan Quality Of Service (QoS) untuk menetapkan tipe-tipe lalu lintas jaringan. Sedangkan QoS adalah kemampuan untuk menggambarkan suatu tingkatan pencapaian didalam suatu sistem komunikasi data.

Manajemen bandwidth adalah sebuah proses penentuan besarnya bandwidth kepada tiap pemakai dalam jaringan komputer. Besarnya bandwidth akan berdampak kepada kecepatan transmisi, Bandwidth internet disediakan oleh provider internet dengan jumlah tertentu tergantung sewa pelanggan. Dengan QoS dapat diatur agar user tidak menghabiskan bandwidth yang di sediakan oleh provider. Bandwidth mempresentasikan jarak keseluruhan atau jangkauan di antara sinyal tertinggi dan terendah pada kanal komunikasi. Pada dasarnya bandwidth mempresentasikan kapasitas dari koneksi, semakin tinggi kapasitas, maka umumnya akan diikuti oleh kinerja yang lebih baik, meskipun kinerja keseluruhan juga tergantung pada faktorfaktor lain, misalnya latency yaitu waktu tunda antara masa sebuah perangkat meminta akses ke jaringan dan masa perangkat itu memberi izin untuk melakukan transmisi (Hekmat, 2005).

Bandwidth management adalah proses mengukur dan mengontrol komunikasi (lalu lintas paket) pada network link untuk menghindari penggunaan melebihi kapasitas pada network link yang dapat mengakibatkan kemacetan jaringan dan kinerja yang buruk. Manajemen bandwidth memberikan kemampuan untuk mengatur bandwidth jaringan dan memberikan level layanan sesuai dengan kebutuhan dan prioritas sesuai dengan permintaan pelanggan.

\subsection{Hierarchical Token Bucket (HTB)}

Hierarchical Token Bucket (HTB) adalah metode pengelompokkan queue atau antrian yang berguna untuk menangani berbagai jenis trafik. Implementasi QoS (Quality of Services) di Mikrotik banyak bergantung pada sistem antrian Hierarchical Token Bucket (HTB). Ada 2 macam queue pada Mikrotik yaitu Simple Queue dan Queue Tree. HTB memungkinkan kita membuat queue menjadi lebih terstruktur, dengan melakukan pengelompokanpengelompokan bertingkat. Yang banyak tidak disadari adalah, jika tidak mengimplementasikan HTB pada Queue (baik Simple Queue maupun Queue Tree), ternyata ada beberapa parameter yang tidak bekerja seperti yang di inginkan. Beberapa parameter yang tidak bekerja adalah priority, dan dual limitation (CIR / MIR). CIR (Comitted Information Rate) adalah batas bawah atau minimal trafik (limit-at) yang dapat diperoleh antrian. Limitat membatasi minimal trafik suatu antrian, tidak peduli dalam kondisi apapun antrian tidak akan mendapt traffik di bawah batas ini. MIR (Maximal Information Rate) adalah batas atas atau maksimal trafik (max-limit) yang bisa diperoleh antrian. Maxlimit membatasi maksimal trafik suatu antrian, dan setiap antrian akan mencapai batas ini jika parent masih memiliki cadangan bandwidth.

Hierarchical Token Bucket (HTB) adalah metode yang berfungsi untuk mengatur pembagian bandwidth, pembagian dilakukan secara hirarki yang dibagi-bagi kedalam kelas sehingga mempermudah pengaturan bandwidth dengan tepat sehingga penggunaannya menjadi maksimal. HTB diklaim menawarkan kemudahan pemakaian dengan teknik peminjaman dan implementasi pembagian trafik yang lebih akurat. Teknik antrian HTB memberikan fasilitas pembatasan trafik pada setiap level maupun klasifikasi, bandwidth yang tidak terpakai dapat digunakan oleh klasifikasi yang lebih rendah. HTB berperan dalam mengontrol penggunaan bandwidth terhadap link yang diberikan kepada klien. HTB memungkinkan penggunaan fisik link single untuk menampilkan multiple link dan untuk mengirimkan 
jenis traffic yang berbeda pada tampilan link yang berbeda. Dengan kata lain, HTB sangat berguna untuk membatasi rating download dan upload client. Dengan demikian client tidak dapat seenaknya menggunakan semua kapasitas bandwidth.

Teknik antrian HTB mirip dengan CBQ hanya perbedaannya terletak pada opsi, HTB lebih sedikit opsi saat konfigurasi serta lebih presisi. HTB dapat dilihat seperti suatu struktur organisasi dimana pada setiap bagian memiliki wewenang dan mampu membantu bagian lain yang memerlukan, teknik antrian HTB sangat cocok diterapkan pada perusahaan dengan banyak struktur organisasi. Secara konseptual, HTB adalah suatu jumlah yang berubah-ubah dari token bucket yang diatur didalam suatu hirarki.

Hierarchical Token Bucket (HTB)

Class structure and Borrowing

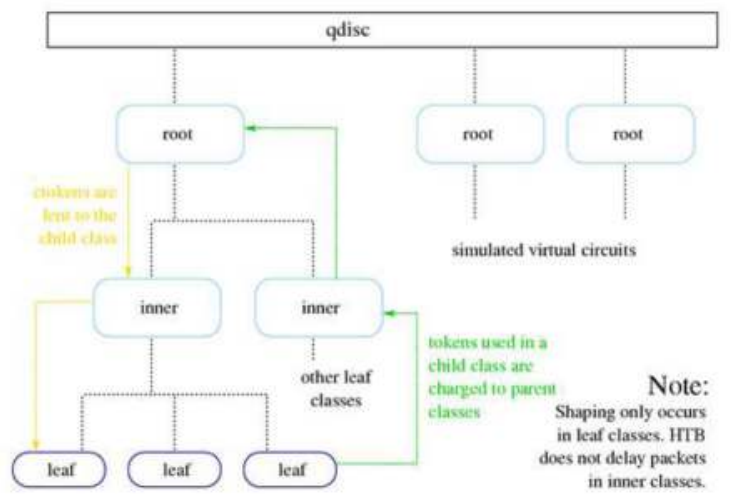

Root qdisc akan berisi satu kelas (skenario kompleks bisa mempunyai berbagai kelas berkait dengan root qdisc). HTB kelas tunggal ini akan diset dengan dua parameter, suatu tingkat tarip dan suatu ceil . Nilai-Nilai ini harus merupakan yang sama untuk the top-level class, dan akan menghadirkan total bandwidth yang tersedia di link / jaringan. Di HTB, rate berarti bandwidth yang dijamin tersedia untuk kelas yang ditentukan dan ceil (ceiling) adalah untuk membatasi berapa banyak yang dapat di pinjam dari kelas lain.

\section{Metodologi}

\subsection{Tempat dan Waktu Penelitian}

Penelitian dan pengambilan data dilakukan di SMK Negeri 22 Jakarta, Jalan Raya Condet, Pasar Rebo, Jakarta Timur. Adapun waktu penelitian dilaksanakan pada bulan Maret 2017 sampai dengan bulan Juni 2017. Penulisan laporan skripsi ini dilaksanakan sejak bulan Maret 2017.

\subsection{Alat dan Bahan Penelitian}

Alat yang digunakan peneliti untuk menganalisis jaringan yang ada adalah sebuah unit Mikrotik Routerboard RB750Gr3.
Perangkat Lunak yang digunakan antara lain Winbox, Web browser Google Chrome, Internet Download Manager, Axence net tools pro 5.0

Dalam tahap ini peneliti akan melakukan metode penelitian rekayasa teknik. Berikut adalah tahapan yang dilakukan

\section{a. Observasi Lapangan}

Pada tahap ini peneliti melakukan pengajuan berkas-berkas penelitian pada lokasi penelitian, dan melakukan pengamatan langsung atau peninjauan secara cermat dan langsung di lapangan atau lokasi penelitian. Tujuan dari dilakukannya observasi adalah agar dapat memperoleh gambaran yang jelas tentang masalah yang akan dijadikan bahan penelitian.

\section{b. Identifikasi Masalah}

Peneliti mengidentifikasi masalah agar mengetahui inti dari penyebab permasalahan sekaligus solusi yang tepat untuk memperbaiki atau menyelesaikan permasalahan tersebut.

\section{c. Pengumpulan Data}

Pengumpulan data dilakukan dengan menggunakan teknik wawancara Data yang digunakan untuk penelitian berupa topologi jaringan di SMK Negeri 22 Jakarta, alokasi Bandwidth, dan spesifikasi peralatan yang digunakan di SMK Negeri 22 Jakarta.

\section{d. Penerapan Metode HTB}

Setelah melakukan observasi lapangan, identifikasi masalah, dan pengumpulan data langkah selanjutnya adalah menerpkan manajemen bandwidth dengan metode HTB.

\section{e. Pengambilan Data}

Data yang diambil adalah data dari uji bandwidth, uji throughput, uji delay dan uji packet loss.

\section{f. Analisis Perbandingan Data Sebelum dan} Sesudah Menggunakan Metode HTB

Setelah mendapatkan hasil yang dibutuhkan yang berupa data dari uji bandwidth, uji throughput, uji delay dan uji packet loss, pada langkah ini adalah membandingkan hasil dari data sebelum menggunakan Hierarchical Token Bucket (HTB) dan setelah menggunakan Hierarchical Token Bucket (HTB) kemudian hasilnya akan dimasukan kedalam tabel agar lebih terlihat jelas perbedaannya.

\section{Hasil dan Analisis}

Berdasarkan hasil analisis dari ke 4 parameter yaitu bandwidth, throughput, delay dan packet loss kita bisa mendapatkan hasil akhir dari penelitian ini. 
Tabel 4.1. Hasil Analisis Akhir Dari Seluruh Parameter

\begin{tabular}{|c|c|c|c|c|}
\hline Web & Average & $\begin{array}{c}\text { Persentase } \\
(\%)\end{array}$ & $\begin{array}{l}\text { Predikat } \\
\text { Tiphon }\end{array}$ & Nilai \\
\hline cnn.com & 480753 & 16.025 & Jelek & 1 \\
\hline facebook.com & 500854 & 16.695 & Jelek & 1 \\
\hline mail.yahoo.com & 229855 & 7.662 & Jelek & 1 \\
\hline Web & $\begin{array}{c}\text { Average } \\
\text { Packet loss }\end{array}$ & $\begin{array}{c}\text { Persentase } \\
(\%)\end{array}$ & $\begin{array}{l}\text { Predikat } \\
\text { Tiphon }\end{array}$ & Nilai \\
\hline cnn.com & 47 & 5 & Bagus & 3 \\
\hline facebook.com & 23 & 2 & $\begin{array}{l}\text { Sangat } \\
\text { Bagus }\end{array}$ & 4 \\
\hline mail.yahoo.com & 24 & 2 & $\begin{array}{l}\text { Sangat } \\
\text { Bagus }\end{array}$ & 4 \\
\hline Web & \multicolumn{2}{|c|}{ Average Delay } & $\begin{array}{l}\text { Predikat } \\
\text { Tiphon }\end{array}$ & Nilai \\
\hline cnn.com & \multicolumn{2}{|c|}{101} & $\begin{array}{l}\text { Sangat } \\
\text { Bagus }\end{array}$ & 4 \\
\hline facebook.com & \multicolumn{2}{|l|}{41} & $\begin{array}{l}\text { Sangat } \\
\text { Bagus }\end{array}$ & 4 \\
\hline \multirow[t]{3}{*}{ mail.yahoo.com } & \multicolumn{2}{|l|}{90} & $\begin{array}{l}\text { Sangat } \\
\text { Bagus }\end{array}$ & 4 \\
\hline & \multicolumn{3}{|c|}{ Hasilpenjum lah an Nilai } & 26 \\
\hline & \multicolumn{3}{|c|}{$\begin{array}{c}\text { Dibagi jumlah Parameter yang di } \\
\text { ukur (9) }\end{array}$} & $26: 9=2.89$ \\
\hline
\end{tabular}

Berdasarkan hasil akhir dari seluruh parameter didapatkan indeks nilai akhir sebesar 2.89. Nilai ini ada dikisaran sedang pada predikat tiphon. Jika dibandingkan dengan tabel 1.1 yaitu uji kualitas layanan sebelum menggunakan metode HTB, hasil setelah menggunakan metode HTB mengalami peningkatan pada parameter throughput pada perangkat pengujian www.cnn.com mengalami peningkatan dari yang sebelumnya sebesar $13.2504 \%$ menjadi $16.025 \%$ dan pada perangkat pengujian www.facebook.com juga mengalami kenaikan dari yang sebelumnya $3.3535 \%$ menjadi $16.695 \%$. Pada parameter packet loss, setelah menggunakan metode HTB mengalami penurunan packet loss dari yang sebelumnya $18 \%$ menjadi $5 \%$ pada www.cnn.com, $19 \%$ menjadi $2 \%$ pada www.facebook.com dan $18 \%$ menjadi $2 \%$ pada www.mail.yahoo.com. Pada parameter delay juga mengalami penurunan nilai delay setelah menggunakan metode HTB dari yang sebelumnya $135 \mathrm{~ms}$ menjadi $41 \mathrm{~ms}$ pada www.facebook.com dan 108 ms menjadi 90 ms pada www.mail.yahoo.com. Dan pada indeks nilai akhir mengalami kenaikan dari yang sebelumnya 2.33 menjadi 2.89 .

\section{Kesimpulan dan Saran}

\subsection{Kesimpulan}

Berdasarkan hasil yang telah didapat maka dapat ditarik kesimpulan sebagai berikut:

1. Manajemen bandwidth dengan metode Hierarchical Token Bucket (HTB) berhasil di terapkan di SMK Negeri 22 Jakarta menggunakan mikrotik RB750Gr3 dengan menggunakan fitur queue tree.

2. Kualitas layanan di SMK Negeri 22 Jakarta saat menggunakaan manajemen bandwidth simple queue mendapatkan indeks nilai akhir sebesar 2.33. Setelah menggunakan manajemen bandwidth queue tree dengan metode Hierarchical Token Bucket (HTB), kualitas layanan di SMK Negeri 22 Jakarta menjadi lebih baik. Pada parameter throughput mengalami kenaikan $2.7746 \%$ pada perangkat pengukuran cnn.com dan $13.3415 \%$ pada facebook.com. Pada parameter packet loss mengalami penurunan $13 \%$ pada cnn.com, $17 \%$ pada facebook.com dan $16 \%$ pada mail.yahoo.com. Pada parameter delay mengalami penurunan dari yang sebelumnya $135 \mathrm{~ms}$ menjadi $41 \mathrm{~ms}$ pada facebook.com dan $108 \mathrm{~ms}$ menjadi $90 \mathrm{~ms}$ pada mail.yahoo.com. Pada indeks nilai akhir mengalami kenaikan dari 2.33 menjadi 2.89 .

\subsection{Saran}

1. Penulis berharap untuk penelitian selanjutnya dapat menambahkan MAC Address sebagai tambahan untuk melakukan manajemen bandwidth. Jadi setiap client hanya bisa mengakses internet dengan satu device

2. Jika ingin dilakukan penambahan bandwidth maka dapat dilakukan dengan 2 cara. Cara yang pertama yaitu dengan menambah jumlah bandwidth yang disewa. Cara ini memerlukan biaya yang cukup besar. Cara yang kedua adalah dengan menggunakan metode load balance. Load balance adalah teknik untuk mendistribusikan beban trafik pada dua atau lebih jalur koneksi secara seimbang. Metode load balance dapat memaksimalkan throughput, memperkecil waktu tanggap dan menghindari overload pada salah satu jalur koneksi. Cara ini membutuhkan dana yang tidak terlalu besar.

\section{Daftar Pustaka:}

Akbar Rizki, Muhammad. 2017. Analisis Kualitas Layanan (Quality of Service) Mikrotik Routerboard Pada Jaringan Internet SMK Negeri 22 Jakarta[skripsi]. Jakarta: Fakultas Teknik, Universitas Negeri Jakarta.

Akmal, Adrian, Fitri Susanti dan M Idham Iskandar. Konfigurasi dan Analisis Manajemen 
Bandwidth pada PC Router Menggunakan Metode HTB (Hierarchy Token Bucket) dan CBQ (Class Based Queue) Studi Kasus Kantor Badan Pertanahan Nasional Bukit Tinggi.Politeknik Telkom Bandung.

Arifin, Yunus. (2012). Implementasi Quality Of Service Dengan Metode HTB (Hierarchical Token Bucket) Pada PT.Komunika Lima Duabelas. Universitas Udayana.

Darmawan, E., Purnama, I., Mahardika, T. I. R., \& Wicaksana, I. W. S. (2012). Bandwidth Manajemen Queue Tree VS Simple Queue. Fakultas Ilmu Komputer, Universitas Gunadarma.

Daniel, Kustanto T dan Saputro. 2009. Membangun Server Internet dengan Mikrotik OS. Jakarta. Gaya Media.

Gunawan, Arif Hamdani 2008, Quality of Service dalam Data Komunikasi

Irfan, Mochamad dan Periyadi, S.T. (2010). Penerapan Bandwidth Management Menggunakan Metode HTB (Hierarchical Token Bucket) Di PT. Neuronworks. Politeknik Telkom Bandung.

Kencana, Surya. 2012. Implementasi Algoritma Per Connection Queue (PCQ) Dalam Algoritma Hierarchical Token Bucket (HTB) Untuk Pembagian Bandwidth Pada Warnet Khelambiqunet. Bandung. Jurnal Politeknik Telkom Bandung.

Nababan, Sabar Saut Martua 2013. Implementasi Bandwidth Management Dan Pengaturan Akses Menggunakan Mikrotik Router OS[skripsi]. Bandung: Fakultas Teknik, Universitas Widyatama.

Riyadi, Valens. (2012). Implementasi QoS pada Mikrotik Diakses pada tanggal 17 mei 2017, dari

(http://www.mikrotik.co.id/artikel_lihat.php?id= 29).

Santosa, B. 2007. Manajemen Bandwidth Internet dan Intranet.

Sofana, Iwan. 2009. CISCO CCNA dan jaringan komputer. Bandung: Informatika.

Syafrizal, Melwin. 2000. Pengantar Jaringan Komputer. Yogyakarta: ANDI Yogyakarta.

Tiphon."Telecommunications and Internet Protocol Harmonization Over Networks (TIPHON) General aspects of Quality of Service (QoS)", DTR/TIPHON-05006 (cb0010cs.PDF).1999.

Wijaya, A. I. \& Handoko, L. B. (2013). Manajemen Bandwidth Dengan Metode HTB (Hierarchical Token Bucket) Pada Sekolah Menengah Pertama Negeri 5 Semarang. Jurnal Teknik Informatika Universitas Dian Nuswantoro.

Yanto. Analisis QoS (Quality of Service) Pada Jaringan Internet (Studi Kasus: Fakultas Teknik Universitas Tanjungpura)[skripsi]. Tanjungpura : Jurusan Teknik Elektro, Fakultas Teknik, Universitas Tanjungpura. 